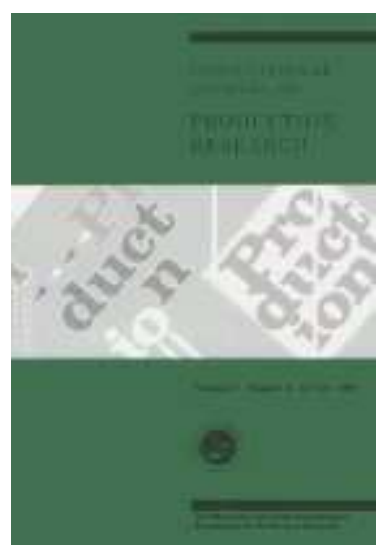

\title{
Capacity and material requirement planning modelling by comparing deterministic and fuzzy models
}

\begin{tabular}{|r|l|}
\hline Journal: & International Journal of Production Research \\
\hline Manuscript ID: & TPRS-2007-IJPR-0229.R1 \\
\hline Manuscript Type: & Original Manuscript \\
\hline $\begin{array}{r}\text { Date Submitted by the } \\
\text { Author: }\end{array}$ & 13-Apr-2007 \\
\hline Komplete List of Authors: & $\begin{array}{l}\text { Mula, J; Polytechnic University of Valencia, Business Management } \\
\text { Poler, R; Polytechnic University of Valencia, Business Management } \\
\text { Garcia-Sabater, José; Polytechnic University of Valencia, Business } \\
\text { Management }\end{array}$ \\
\hline Keywords (user): & PRODUCTION PLANNING, FUZZY METHODS \\
\hline & \multicolumn{2}{|l}{} \\
\hline
\end{tabular}

\section{scholarONE" \\ Manuscript Central}




\section{Summary}

A model for the capacity and material requirement planning problem with uncertainty in a multi-product, multi-level and multi-period manufacturing environment is proposed. An optimization model is formulated which takes into account the uncertainty that exists in both the market demand and capacity data, and the uncertain costs for backlog. This work uses the concept of possibilistic programming by comparing trapezoidal fuzzy numbers. Such an approach makes it possible to model the ambiguity in market demand, capacity data, cost information, etc. that could be present in production planning systems. The main goal is to determine the master production schedule, stock levels, backlog, and capacity usage levels over a given planning horizon in such a way as to hedge against the uncertainty. Finally, the fuzzy model and the deterministic model adopted as the basis of this work are compared using real data from an automobile seat manufacturer. The paper concludes that fuzzy numbers could improve the solution of production planning problems.

Keywords: Production planning, Uncertainty modelling, Fuzzy methods, Possibility theory.

\section{Introduction}

Many possible forms of uncertainty could be present in the decision environment of a production planning system such as market demand, capacity data, cost information, etc. The consideration of uncertainty in manufacturing systems means a great advance, in terms of describing reality, but it may pose problems for solving the model. Models for production planning which do not recognize

\footnotetext{
** This research has been carried out in the framework of a project funded by the Polytechnic University of Valencia, titled 'Development of fuzzy mathematical programming models for production planning in context of uncertainty. Application to an industrial company of the automobile sector' (Ref. PPI-06-05/5703).

* Corresponding author. Josefa Mula, Dpto. Organización de Empresas, Escuela Politécnica Superior de Alcoy, Edificio Ferrándiz y Carbonell, 2, 03801 Alcoy (Alicante), SPAIN. Tel.: + 349665284 23. Fax: + 34 9665285 85. E-mail addresses: fmula@ cigip.upv.es, rpoler@ cigip.upv.es, jpgarcia@doe.upv.es.
} 
uncertainty can be expected to generate inferior planning decisions as compared to models which explicitly take into account uncertainty. Over the years, many researches and applications aimed to formalize the uncertainty in production planning systems. Mula et al. (2006b) review some of the existing literature (82 citations from 1983 to 2004) about uncertainty modelling in production planning problems.

Different stochastic modelling techniques based on probability distributions have been successfully applied to production planning problems with randomness, which comes from the random nature of events, and deals with uncertainty regarding membership or non-membership of an element in a set. Stochastic programming is appropriate if parameters are given as random variables. Bitran and Yanasse (1984) propose deterministic approximations to a non-sequential capacity planning model and analyze its effectiveness when the demand is characterized by standard probability distributions. Paraskevopoulos et al. (1991) use a robust approach to solve a production capacity planning problem with a stochastic demand. Escudero et al. (1993) analyze different modelling approaches for the production and capacity problem using stochastic programming. Gfrerer and Zäpfel (1995) present a multi-period hierarchical production planning model with two planning levels, i.e. aggregate and detailed, and with uncertain demand. Kira et al. (1997) propose a hierarchical approach to model the multi-period and multi-product production programming problem with a finite set of demands through stochastic linear programming. Gupta and Maranas (2003) and Sodhi (2005) address the problem of supply chain production planning under demand uncertainty using a stochastic programming based approach.

When considering uncertainty in models, some difficulties can arise to estimate parameters such as high cost in acquiring data information and lack of statistical observations. Since sufficient data are not always available for predicting uncertain parameters, the choice of the fuzzy set theory is more logical and convincing for the expression of the uncertainty by the expert knowledge. Also, probability distributions derived from evidences recorded in the past are not always reliable because of market changes, which influence demand or backlog costs, or technological innovation, which in turn has an influence on capacity data. In such situations, the fuzzy set theory has been 
used to model systems that are difficult to define accurately (Bellman and Zadeh, 1970; Dubois and Prade, 1980; Zimmermann, 1996). This theory represents an attractive tool to support the production planning research when the dynamics of the manufacturing environment limits the specification of the model objectives, constraints and parameters. Guiffrida and Nagi (1998) provide an exhaustive literature survey on the fuzzy set theory applications in production management research.

It is necessary to distinguish between the fuzziness or flexibility in constraints and goals and the uncertainty of the data or epistemic uncertainty. Flexibility is modelled by fuzzy sets and may reflect the fact that constraints or goals are linguistically formulated; their satisfaction is a matter of tolerance and degrees, or fuzziness (Bellman and Zadeh, 1970). Epistemic uncertainty is concerned with ill-known parameters modelled by fuzzy intervals in the possibility theory setting (Zadeh 1978; Dubois and Prade 1988).

A few research works have been carried out in the area of fuzzy production planning. Some applications of flexible programming in production planning problems can be found in Miller et al. (1997), Pendharkar (1997), Itoh et al. (2003), Melian and Verdegay (2005) and Mula et al. (2006a). Other applications of possibilistic programming in production planning problems can be found in Gen et al. (1992), Inuiguchi et al. (1994), Hsu and Wang (2001), Wang and Fang (2001), Lodwick and Bachman (2005) and Wang and Liang (2005).

With the aim to demonstrate the usefulness and significance of the fuzzy programming, in this paper a possibilistic approach is applied to a capacity and material requirement planning problem with uncertain data. The main contribution of this paper is that it shows an example where fuzzy numbers could improve the solution. This work uses a fuzzy linear programming approach based on the possibility theory to generate an optimal fuzzy solution. In this context, the survey works by Kacprzyk and Orlovsky (1987), Delgado et al. (1994), Rommelfanger (1996) and Zimmermann (2000) show some possibilities of how the fuzzy set theory can be accommodated within linear programming. 
This paper is arranged as follows: firstly in Section 2, we present a linear programming (LP) model for production planning with a deterministic structure. In Section 3, the LP model is transformed into a fuzzy model for production planning with uncertain data. Section 4 uses a realworld application to illustrate the potential savings which can be attained by using fuzzy models in a fuzzy decision-making environment. Section 5 offers some conclusions.

\section{Formulation of the linear programming model}

This linear programming (LP) model, originally proposed by Mula et al. (2006a), is adopted as the basis of this work. It is a model for the optimization of the production planning problem in a capacity constrained, multi-product, multi-level and multi-period manufacturing environment. The LP model is formulated as follows.

Decision variables and parameters for the model are defined in Table 1.

Table 1. Decision variables and model parameters.

$$
\begin{aligned}
& \text { Min Z }=\sum_{i=1}^{I} \sum_{t=1}^{T}\left(c p_{i} P_{i t}+c i_{i} I N V T_{i t}+c b_{i} B_{i t}\right)+\sum_{r=1}^{R} \sum_{t=1}^{T}\left(c t u n_{r t} T_{u n}+c t o v_{r t} T_{r t} v_{r t}\right) \\
& \text { s.t. } \\
& I N V T_{i, t-1}+P_{i, t-T S_{i}}+S R_{i t}-I N V T_{i, t}-B_{i, t-1}-\sum_{j=1}^{I} \alpha_{i j}\left(P_{j t}+S R_{j t}\right)+B_{i t}=d_{i t}, \\
& \sum_{i=1}^{I} A R_{i r} P_{i t}+T u n_{r t}-T_{o v}=1, \ldots, I, t=1, \ldots, T \\
& B_{i t}=0, i=1, \ldots, I \\
& P_{i t}, I N V T_{i t}, B_{i t}, T_{u n}, \operatorname{Tov}_{i t} \geq 0, i=1, \ldots, I, r=1, \ldots, R, t=1, \ldots, T
\end{aligned}
$$

Equation (1) shows the total costs to be minimized: the costs of the inventories $c i_{i}$, the costs of the extra time used by resources, ctov $_{r t}$, and the costs of the idle time of resources, ctun $_{r t}$. The LP model includes a plan to satisfy the backlogs penalized with a cost, $c b_{i}$. It is assumed that this cost is linear to the number of backlogs in every period. 
The balance equations for the inventory are given by the group of constraints (2). These equations take into account the backlogs which behave as a negative inventory. It is important to highlight the consideration of parameter $S R_{i t}$ that guarantees the continuity of the production plan throughout the successive runs carried out during a given planning horizon.

Production in each period is limited by the availability of a group of shared resources. Equation (3) considers the capacity limits of these resources. This equation has been thought in a similar way to the model proposed by Billington et al. (1983), although the fixed costs/setup times have been ignored since we are performing an aggregate production planning. The decision variables $T u n_{r t}$ and $T o v_{r t}$ are not limited by any established parameter but are penalized with the corresponding costs in the objective function. This is to provide the model with the best generality possible. The constraint of these variables for specific applications could be easily considered taking into account that if those constraints are exceeded, the solution of the model might not be feasible.

A constraint has also been added (4) to finish the backlogs in the last period, $T$, of the planning horizon.

The model also contemplates the non negativity constraints (5) for the decision variables. Finally, the decision variables $P_{i t}, I N V T_{i t}$ and $B_{i t}$ will be defined as continuous or integer variables, depending on the manufacturing environment where the model is applied.

The LP model includes a small number of constraints with the objective of providing a model that is as generic as possible. Other types of more specific constraints from the manufacturing environment where the model is applied can be easily added, such as, alternative production processes for some products, recruiting variables and manpower discharges for resources planning and production, overtime or stock levels, etc. Some of these constraints are included in the model proposed by Escudero (1994).

The solution that satisfies the constraints and minimizes the objectives specified previously should be used dynamically, i.e. only decisions related to the first periods of the planning horizon will be executed. Then, when new information on demand, availability of resources, bill of materials, lead times, costs, etc. arrive; the model should be upgraded and re-executed. 


\section{A possibilistic programming approach}

When the backlog costs, the market demand, the required capacity or the available capacity are uncertain data for the planner, the deterministic model becomes insufficient to describe the situation and we try to model and solve the mid-term production planning problem with a possibilistic programming approach.

This model adopts the fuzzy numbers comparison approach proposed by Negi and Lee (1993). The authors use the concept of possibilistic programming to compare fuzzy numbers and overcome the difficulties to obtain the possibility distribution due to the non-linearity by assuming a level of attainment of the possibility. Therefore the problem becomes linear.

We consider fuzzy technological coefficients, fuzzy cost coefficients and fuzzy right-hand-side numbers represented by a trapezoidal fuzzy number ( $\operatorname{Tr} F M$, although different types of fuzzy numbers might be used.

A $\operatorname{TrFN}, \tilde{b}$, is defined as follows, $\tilde{b}=\left\{\underline{b}, b_{1}, b_{2}, \bar{b}\right\}$, where $\underline{b}$ is the smallest possible value, $b_{1}$ and $b_{2}$ are the main values and $\bar{b}$ is the largest possible value (Negi and Lee, 1993).

The so-called membership function associated with $\tilde{b}$ is $\mu_{\tilde{b}}(b, \theta), \theta \in[0,1]$, where $\theta$ is the maximum value of the membership function, thus when $b_{2} \geq b \geq b_{1}$, then:

$$
\mu_{\tilde{b}}(b, \theta)=\left\{\begin{array}{cc}
0, & \text { if } b<\underline{b} \text { or } b>\bar{b}, \\
\frac{(b-\underline{b}) \theta}{b_{1}-\underline{b}} & \text { if } b_{1} \geq b \geq \underline{b} \\
\theta & \text { if } b_{2} \geq b \geq b_{1} \\
\frac{(\bar{b}-b) \theta}{\bar{b}-b_{2}} & \text { if } \bar{b} \geq b \geq b_{2}
\end{array}\right.
$$

$$
\text { where } \theta \geq \mu_{\tilde{b}}(b, \theta) \geq 0 \text { (see Figure 1). }
$$


Figure 1. Trapezoidal fuzzy number.

The comparison of two fuzzy numbers depends on the type of fuzzy number. Iskander (2002) uses the comparison of two triangular fuzzy numbers (TFNs): TrFN and TFN. Here, the comparison approach is used for two TrFNs according to Negi and Lee (1993).

If $\tilde{A}$ and $\tilde{B}$ are two TrFNs, with the same $\theta$, where $\tilde{A}=\left\{\underline{a}, a_{1}, a_{2}, \bar{a}\right\}$ and $\widetilde{B}=\left\{\underline{b}, b_{1}, b_{2}, \bar{b}\right\}$, the possibility that $\widetilde{A} \geq \widetilde{B}$ is defined as follows:

$\operatorname{Pos}(\tilde{A} \geq B)=\left\{\begin{array}{cc}\theta, & \text { if } a_{2} \geq b_{1}, \\ \frac{(\bar{a}-\underline{b}) \theta}{\left(\bar{a}-a_{2}\right)+\left(b_{1}-\underline{b}\right)}, & \text { if } b_{1} \geq a_{2}, \bar{a} \geq \underline{b}, \\ 0, & \text { if } \underline{b} \geq \bar{a},\end{array}\right.$

While the possibility that $\widetilde{A}>\widetilde{B}$ is defined as:

$$
\operatorname{Pos}(\widetilde{A}>B)=\left\{\begin{array}{cc}
\theta, & \text { if } a_{2} \geq \bar{b}, \\
\frac{\left(\bar{a}-b_{2}\right) \theta}{\left(\bar{a}-a_{2}\right)+\left(\bar{b}-b_{2}\right)}, & \text { if } \bar{b} \geq a_{2}, \bar{a} \geq b_{2}, \\
0, & \text { if } b_{2} \geq \bar{a},
\end{array}\right.
$$

We include $\operatorname{TrFNs}$, i.e. $c \tilde{b}_{i}, \tilde{d}_{i t}, A \tilde{R}_{i r}$ and $C A \tilde{P}_{r t}$, representing the fuzzy backlog cost, market demand, required capacity and available capacity, respectively, in Equations (1), (2) and (3) as follows:

$\operatorname{Max} \mathrm{Z}=-\sum_{i=1}^{I} \sum_{t=1}^{T}\left(c p_{i} P_{i t}+c i_{i} I N V T_{i t}+c \tilde{b}_{i} B_{i t}\right)-\sum_{r=1}^{R} \sum_{t=1}^{T}\left(\operatorname{ctun}_{r t} \operatorname{Tun}_{r t}+\operatorname{ctov}_{r t} \operatorname{Tov}_{r t}\right)$

s.t.

$$
\begin{array}{r}
I N V T_{i, t-1}+P_{i, t-T S_{i}}+S R_{i t}-I N V T_{i, t}-B_{i, t-1}-\sum_{j=1}^{I} \alpha_{i j}\left(P_{j t}+S R_{j t}\right)+B_{i t} \leq \tilde{d}_{i t}, \\
i=1, \ldots, I, t=1, \ldots, T \\
-I N V T_{i, t-1}-P_{i, t-T S_{i}}-S R_{i t}+I N V T_{i, t}+B_{i, t-1}+\sum_{j=1}^{I} \alpha_{i j}\left(P_{j t}+S R_{j t}\right)-B_{i t} \leq-\tilde{d}_{i t}, \\
i=1, \ldots, I, t=1, \ldots, T
\end{array}
$$




$$
\begin{aligned}
& \sum_{i=1}^{I} \tilde{A} R_{i r} P_{i t}+\text { Tun }_{r t}-\text { Tov }_{r t} \leq \tilde{C A} P_{r t}, r=1, \ldots, R, t=1, \ldots, T \\
& -\sum_{i=1}^{I} \tilde{A R_{i r}} P_{i t}-T_{u n}+\operatorname{Tov}_{r t} \leq-C A \tilde{P}_{r t}, r=1, \ldots, R, t=1, \ldots, T
\end{aligned}
$$

The crisp objective function to minimize in the LP model (1) has become the fuzzy objective function to maximize (9).

The equality equation of the inventory balance of the LP model (2) has become Equations (10) and (11) in the fuzzy model. In the same way, the equality equation of the available capacity of the LP model (3) has become the two inequality Equations (12) and (13) in the fuzzy model.

The non fuzzy constraints (4) and (5) should be incorporated into the fuzzy model, remaining unalterable.

In accordance with the fuzzy numbers comparison approach proposed by Negi and Lee (1993), and using the concept of the $\alpha$-level by Zadeh (1965), i.e. the ordinary set (non fuzzy) $A_{\alpha}$ of elements that belong to the fuzzy set $\tilde{A}$ at least with the $\alpha$ grade, is denominated the $\alpha$-level set of $\tilde{A}$, or $\alpha$-cut:

$$
\widetilde{A}_{\alpha}=\left\{x \in X \mid \mu_{A}(x) \geq \alpha, 0 \leq \alpha \leq 1\right\}
$$

In order to solve the problem, $\alpha$ settles down parametrically to obtain the value of the objective function for each of these $\alpha \in[0, \theta]$. The result is, however, a fuzzy set and the planner has to decide which pair $(\alpha, z)$ considers the optimum if a crisp solution is to be obtained. Let $\alpha$ be determined by the planner for any given value of $\theta, \theta \in[0,1]$. The equivalent crisp model is represented as follows:

$$
\begin{aligned}
& \text { Max } Z \\
& \text { s.t. } \\
& I N V T_{i, t-1}+P_{i, t-T S_{i}}+S R_{i t}-I N V T_{i, t}-B_{i, t-1}-\sum_{j=1}^{I} \alpha_{i j}\left(P_{j t}+S R_{j t}\right)+B_{i t} \leq\left(\frac{\theta}{\alpha}-1\right) \bar{d}_{i t}+d_{i t 2}, \\
& i=1, \ldots, I, t=1, \ldots, T \\
& I N V T_{i, t-1}+P_{i, t-T S}+S R_{i t}-I N V T_{i, t}-B_{i, t-1}-\sum_{j=1}^{I} \alpha_{i j}\left(P_{j t}+S R_{j t}\right)+B_{i t} \leq \bar{d}_{i t}, \\
& i=1, \ldots, I, t=1, \ldots, T
\end{aligned}
$$




$$
\begin{aligned}
& -I N V T_{i, t-1}-P_{i, t-T S_{i}}-S R_{i t}+I N V T_{i, t}+B_{i, t-1}+\sum_{j=1}^{I} \alpha_{i j}\left(P_{j t}+S R_{j t}\right)-B_{i t} \leq\left(\frac{\theta}{\alpha}-1\right) \underline{d}_{i t}-d_{i t 1}, \\
& -I N V T_{i, t-1}-P_{i, t-T S_{i}}-S R_{i t}+I N V T_{i, t}+B_{i, t-1}+\sum_{j=1}^{I} \alpha_{i j}\left(P_{j t}+S R_{j t}\right)-B_{i t} \leq-\underline{d}_{i t}, \\
& \sum_{i=1}^{I}\left(\frac{\theta}{\alpha} A R_{i r 2}-A R_{i r 2}+\overline{A R}_{i r}\right) P_{i t}+T u n_{r t}-T o v_{r t} \leq\left(\frac{\theta}{\alpha}-1\right) \overline{C A P}_{r t}+C A P_{r t 2}, \\
& \sum_{i=1}^{I}\left(\frac{\theta}{\alpha} A R_{i r 2}-A R_{i r 2}+\overline{A R}_{i r}\right) P_{i t}+T u n_{r t}-T o v_{r t} \leq \overline{C A P}_{r t}, r=1, \ldots, R, t=1, \ldots, T \\
& -\sum_{i=1}^{I}\left(\frac{\theta}{\alpha} A R_{i r 2}-A R_{i r 2}+\overline{A R}_{i r}\right) P_{i t}-T u n_{r t}+T o v_{r t} \leq\left(\frac{\theta}{\alpha}-1\right) \underline{C A P}_{r t}-C A P_{r t 1}, \\
& -\sum_{i=1}^{I}\left(\frac{\theta}{\alpha} A R_{i r 2}-A R_{i r 2}+\overline{A R}_{i r}\right) P_{i t}-T u n_{r t}+T o v_{r t} \leq-\underline{C A P}_{r t}, r=1, \ldots, R, t=1, \ldots, T \\
& z \leq-\sum_{i=1}^{I} \sum_{t=1}^{T}\left(c p_{i} P_{i t}+c i_{i} I N V T_{i t}+\left(\overline{c b}_{i}-\frac{\alpha}{\theta} \overline{c b}_{i}+\frac{\alpha}{\theta} c b_{i 2}\right) B_{i t}\right)-\sum_{r=1}^{R} \sum_{t=1}^{T}\left(c t u n_{r t} T u n_{r t}+c t o v_{r t} T o v_{r t}\right) \\
& z \geq-\sum_{i=1}^{I} \sum_{t=1}^{T}\left(c p_{i} P_{i t}+c i_{i} I N V T_{i t}+c b_{i 2} B_{i t}\right)-\sum_{r=1}^{R} \sum_{t=1}^{T}\left(c t u n_{r t} T u n_{r t}+c t o v_{r t} T o v_{r t}\right),
\end{aligned}
$$

Additionally, the non fuzzy constraints (4) and (5) should be incorporated into this model, remaining unalterable.

When applying the modifications proposed by Iskander (2002) to the approach developed by Negi and Lee (1993), Equations (24) and (25) are eliminated and the objective function (15) is replaced by Equation (26) as follows:

$\operatorname{Max} \mathrm{Z}=-\sum_{i=1}^{I} \sum_{t=1}^{T}\left(c p_{i} P_{i t}+c i_{i} I N V T_{i t}+\left(\overline{c b}_{i}-\frac{\alpha}{\theta} \overline{c b}_{i}+\frac{\alpha}{\theta} c b_{i 2}\right) B_{i t}\right)-\sum_{r=1}^{R} \sum_{t=1}^{T}\left(\operatorname{ctun}_{r t} \operatorname{Tun}_{r t}+\operatorname{ctov}_{r t}\right.$ Tov $\left._{r t}\right)$

The approach by Iskander (2002) reduces the number of decision variables. Furthermore, a sensitivity analysis of the values $\theta$ and $\alpha$ can be carried out. If the planner does not participate in the definition of $\theta$ and $\alpha$, these values can be fixed at 1, eliminating the redundant constraints. Finally, the adopted approach can be applied if different values of $\alpha$ (different levels of possibility) are given to different constraints. The main disadvantage of this model in relation to the LP model is 
that it requires the planner to specify more data, such as the values of $\theta$ and $\alpha$. Nonetheless, it allows the uncertain data (backlog cost, demand, required capacity and available capacity) to be formalized through the definition of the $\operatorname{TrFNs}: c \widetilde{b}_{i}, \widetilde{d}_{i t}, A \widetilde{R}_{i r}$, and $C A \widetilde{P}_{r t}$.

\section{Application in an automobile seat manufacturer}

The proposed models have been evaluated using data from an automobile seat manufacturer. The company is an assembly plant for car seats belonging to a multinational group leader in the supply of seats in the automobile sector. Currently, the company uses a production planning system that is integrated in an ERP system based on a standard MRP II. Nevertheless, the company only uses the MRP II module for material supply planning. The company considers it has no capacity problems given that the car seat assembly plant is a flexible plant, designed according to automobile assembler requirements and with the possibility of using extra capacity from other plants of the industrial group. Therefore, the main objective of the generation of a production plan is to supply material at the minimum cost which is subordinated to the constraint of avoiding stock shortages.

The company receives the demand information from the automobile assembler on a weekly basis (every Monday) with a planning horizon for six months. However, these demand forecasts are rarely accurate (Mula et al. 2005). Therefore, in this section we will validate if the fuzzy model for production planning that we propose in this paper can be a useful tool for the decision-making process of the production planners in an uncertain decision environment.

\subsection{Assumptions}

The assumptions to carry out the computational experiment are summarized as follows:

- $\quad$ The study considers a representative single part called RPN (Representative Part Number). The research of this representative part allows us to generalize its behaviour to any item in the system. Moreover, it is important to understand the behaviour of a single part as the basis for additional research of the proposed model.

- The decision variables, $P_{i t}, I N V T_{i t}$ and $B_{i t}$ are considered integer. Despite this being a mixed integer linear programming problem, the mathematical relationships established in the 
section between the fuzzy model and the equivalent linear programming models are the same as if it were a linear programming problem.

- Only the final product has external demand.

- A six-monthly planning horizon with a weekly period planning has been considered.

- Firm orders from the automobile maker cannot be rejected.

- Backlog for the final product RPN are considered but with a high penalization cost, since the required service level for a sequenced and synchronized supplier of seats for automobiles is $100 \%$.

- The company, which has implemented a JIT philosophy, officially states it does not use safety stocks but uses safety times for some of the components to be supplied to them.

- Once the seat assembler sends the purchase orders to its suppliers, these cannot reject them. Moreover, all the materials are supplied according to the production program, so lead times for supplied materials are assumed as constant values.

- The production stage is considered to be single, i.e. all the materials are supplied based on demand forecasts and the final assembly of seats begins after receiving firm orders, in other words, a production strategy denominated Assembly-to-Order (Fumero and Vercellis, 1994).

- A single productive resource restricts production: the assembly line.

- The decision variable of overtime $\left(T o v_{r t}\right)$ for the RPN part refers to the hours of assembly to be subcontracted externally, rather than the overtime used to carry out this work at the factory itself. Therefore, overtime limits are not considered. It is assumed that the subcontracted products will be ready just when required without lead time changes.

- The unit costs of undertime $\left(\right.$ ctun $\left._{r t}\right)$ are considered null.

- For the fuzzy model, the parameter $\theta$ has been established at 1 while the parameter $\alpha$ is an aspiration level $(0 \leq \alpha \leq \theta)$ with a step of 0.1 . In this particular case, we will select the $\alpha$ value whose best results provide most of the evaluated indicators (see the next section). 
- Moreover, the fuzzy cost coefficient, $c \tilde{b}_{i}=\left\{c b_{i}, c b_{i 1}, c b_{i 2}, \overline{c b_{i}}\right\}$, the fuzzy right-hand-side number, $\quad \widetilde{d}_{i t}=\left\{\underline{d_{i t}}, d_{i t 1}, d_{i t 2}, \overline{d_{i t}}\right\}, \quad$ and the fuzzy technological coefficients, $A \widetilde{R}_{i r}=\left\{\underline{A R_{i r}}, A R_{i r 1}, A R_{i r 2}, \overline{A R}_{i r}\right\}$ and $C A \widetilde{P}_{r t}=\left\{\underline{C A P_{r t}}, C A P_{r t 1}, C A P_{r t 2}, \overline{C A P_{r t}}\right\}$ required by the fuzzy model, have been defined following the company's criteria. For instance, in the case of the demand information:

- $d_{i t 2}$ is considered to be the demand information received by the company,

$\circ d_{i t 1}$ is obtained by decreasing the value of $d_{i t 2}$ by $5 \%$,

- $d_{i t}$ is obtained by decreasing the value of $d_{i t 2}$ by $10 \%$, and

○ $\overline{d_{i t}}$ is obtained by increasing the value of $d_{i t 2}$ by $10 \%$.

- Production variations due to quality or machine failures are not considered.

- Planned orders are recalculated for every planning period, while the scheduled receipts of the components are considered to be 'firm'.

- The execution measures for each model (LP model and fuzzy model) performance are: production, inventory, backlog and overtime costs.

- The technical and economic information of the part RPN are considered, as is the demand information for a planning horizon of 30 weeks, from 11/11/2002 to 02/06/2003.

Given the importance of production planning and the existing models with deterministic approaches, the experiment compares the performance of the deterministic approach proposed in Section 2, the LP model, with the possibilistic approach proposed in Section 3. The aim to this comparison is to demonstrate the usefulness and appropriateness of these fuzzy models operating in an uncertain decision-making environment. Thus, each model is executed for every period $(t=$ $1 \ldots 30$ ) at a rolling horizon of initially 30 periods and later on $29,28,27, \ldots, 1$, updating the demand values, the inventory, the backlog and the scheduled receipts of components. The main difference between the foreseen performances of both models is that the LP model will generate a production plan for every period and will assume certain values of all the model parameters, while the fuzzy 


\subsection{Implementation and resolution}

The dynamic character of the production planning problem and the integrity requirements on some variables are taken into consideration through the architecture developed for the production planning of the proposed models, as illustrated in Figure 3.

The models have been implemented with the modelling language MPL V4.11 (Maximal Software Co. 2000). MPL can use different relational databases to manage the model data with only minor adjustments. This provides very good data validation and data integrity tools, and is capable of handling a large amount of data. Moreover, it provides easy access to the corporate data, which at the same time facilitates the process of updating the data required by the models. The problem is then solved by the mixed integer programming problem solver CPLEX 6.6 (CPLEX Optimization Co. 1994), and the solution is imported back into the database.

Figure 3. Models architecture.

The detailed data of this computational experiment and the MPL models can be found in Mula (2004). 


\subsection{Evaluation method}

To evaluate the models, the following indicators have been defined to be measured: (i) the average service level; (ii) number of minimum inventory levels; (iii) planning nervousness respect to the planned period and the planned quantity; (iv) total costs, and (v) computational efficiency. These indicators have been selected in order to evaluate the model outputs given by the activity of the decision variables.

\subsubsection{Average service level}

The average service level, expressed as a percentage, is determined only for the final product $R P N$ as follows:

Average service level $(\%)=\sum_{t=1}^{T} \frac{\left(1-\frac{B_{i t}}{\sum_{t^{\prime}=1}^{t} d_{i t^{\prime}}}\right) \times 100}{T} \quad \forall i=R P N$

\subsubsection{Minimum inventory levels}

In order to evaluate the number of minimum inventory levels, the average total quantity of inventory of products (final product, raw materials and components) is determined for each period in the planning horizon. Then, we count the number of times that a model yields the lowest inventory.

\subsubsection{Planning nervousness}

Here we explain criterion (iii) in detail. A "nervous" or unstable planning is referred to a plan which undergoes important variations when incorporating the demand changes between what is foreseen and observed in successive plans, as defined by Sridharan et al. (1987). Whybark and Williams (1976) noted a difference between: (i) demand timing uncertainty, that is reflected by timing changes; and (ii) demand quantity uncertainty, that occurs when the demand quantities are increased or decreased. Therefore, the planning nervousness can be measured according to:

The demand changes in the planned period. The number of times that a planned order is rescheduled irrespectively of the planned quantity (Heisig, 1998). This case is directed to minimize disruptions in the production sequence, since this would imply extra setup time. Van Donselaar et 
al. (2000) propose a measure of the planning nervousness focused on the setup costs for a manufacturing company of trucks in an MRP environment. The rule is summarized as so:

At time $t$ we check for each period $t+x(x=0,1,2, \ldots, T-1)$ :

- If there is a planned order in $t+x$ and this order is not planned in the next planning run, we increase the number of reschedules by 1 .

- If there was no planned order in $t+x$ and there is one in the next planning run, we increase the number of reschedules by 1 .

The demand changes in the planned quantity. The number of times that the quantity of a planned order is modified (De Kok and Inderfurth, 1997). This case focuses on minimizing the stock shortages or excesses, since this would imply higher costs of backlog and a holding of inventories. The rule is described as follows:

In the period $t=1, \ldots, T$, where $T$ is the number of periods that forms the planning horizon, $t+x(x$ $=0,1,2, \ldots, T-1)$ is checked for every period:

- If a planned order exists in the period $t+x$, and if the quantity of the planned order is not the same as in the next planning run, we increase the number of reschedules by 1 .

While computing planning nervousness, we measure the number of changes. Another way to compute would be to take into account the rate of the changes.

\subsubsection{Total costs}

Total costs are the sum of all the costs generated in each period of the considered planning horizon, derived from the production plans provided by the model.

\subsubsection{Computational efficiency}

The parameter computational efficiency measures the computational effort needed to resolve each model. After solving the model, MPL automatically creates a standard solution file with the following statistics: The number of barrier iterations before reaching the solution; the number of variables; the number of variables that are integer; the number of constraints; the number of nonzero elements for the full matrix that was stored; the matrix density of constraints; the CPU time it takes to obtain the solution. 


\subsection{Evaluation of the results}

Table 2 presents the quantitative results of our application in terms of the indicators previously described. In the case of the fuzzy model that provides a fuzzy solution, the fuzzy set of the decision has been obtained. Then, it has been chosen as a crisp solution which obtains the best results in the highest number of the evaluated indicators. Only the selected crisp solution will be considered for this model throughout this section, where the parameter $\alpha$ was established at 0.9 .

Table 2. Evaluation of the results for all planning horizons.

Both models present an average service level of between 99.44 and $99.49 \%$. The fuzzy model provides a slightly better value at the service level (99.49\%). Conversely, the fuzzy model generates a higher number of minimum inventory levels, i.e. 35 of the 46 evaluated items present lower inventories with the production plans obtained by the fuzzy model in contrast with the 8 items with lower inventories provided by the LP model.

The models presented a similar nervousness in relation to the planned time period. On the other hand, the fuzzy model presents the best value of nervousness in relation to planned quantity.

The fuzzy model also generates lower total costs than the LP model. These differences in the total costs are mainly due to two aspects:

i) The consideration of possible future variations on the demand which may lead to a larger production and/or inventories with the objective of avoiding the strongly penalized backlogs.

ii) The strict constraints of the deterministic model, where the required capacity and the available capacity of the assembly line are rigidly fixed.

Table 3. Efficiency of computational experiments for only one execution (first week).

With regard to the computational efficiency, both models can obtain the optimal solution of the mixed integer linear programming with no iterations in the first production plan execution. Obviously, 
the number of iterations can change in the rest of production plan executions, depending on the input data. On the other hand, both models have the same number of variables and integer variables, but the fuzzy model requires more non zero elements (thus, a larger array density) and more constraints than the LP model, which could imply greater requirements of information storage. Finally, the LP model uses less CPU time than the fuzzy model.

Therefore, the fuzzy model has provided freedom of action with regard to problems where uncertain values appear with a minimum increment of information storage requirements and a moderate increase of the required CPU time.

From the empirical research carried out, we can draw the following conclusions:

- Neither model behaves worse or better for all the evaluation criteria.

- The fuzzy model behaves better than the LP model in four of the evaluation criteria.

- The fuzzy model displays the best behaviour in relation to Service Level and Total Costs, two of the most important evaluation criteria for the company.

From an economic point of view, the fuzzy model obtained the best marks, i.e. it generates the least Total Costs and, therefore, it would be selected as the most appropriate model for application. On the other hand, if the company is looking for a model which behaves best in all the evaluation criteria, the fuzzy model would also be selected.

\section{Conclusions}

In this paper, a linear programming (LP) model has been presented in order to solve the midterm production planning problem in a capacity constrained, multi-product, multi-level and multiperiod manufacturing environment. The LP model assumes that demand is known and that production will follow the generated plan to a great extent. In many manufacturing environments however, such as the automobile industry, these decisions have to be made under conditions of uncertainty in parameters as important as costs, market demand or capacity data.

A model based on fuzzy mathematical programming for production planning under conditions of uncertainty has been proposed. It is important to highlight that the objective of the fuzzy model for production planning proposed in this research is not to replace deterministic models, rather to 
provide a solid and efficient option for its application in environments with conditions of uncertainty where the use of deterministic models are not completely realistic.

The proposed models have been applied to a company dedicated to the assembly of car seats. It is important to clarify that the decision makers from the company accept and understand the models and the differences between them, but only from the point of view of users; that is, they can not build them up or modify them.

Generally speaking, the fuzzy model structure has been able to increase group satisfaction (level of service, inventory levels, planning nervousness and total costs) without causing an explosive growth of computational effort. Thus, this research work demonstrates that models based on fuzzy mathematical programming are sound for modelling production planning processes, and that an economic benefit can exist when these are used in comparison with traditional deterministic models. Fuzzy models can also be reformulated as equivalent crisp models that can be solved efficiently with standard software, such as CPLEX.

Finally, the literature approaches to cope with different forms of uncertainty in production planning systems is considerable. Nevertheless, new approaches for production planning and control are still necessary to manage uncertainty. Our position is that the fuzzy sets theory is generally an adequate methodology that can mean a great advance in production planning research. Future plans are related to: (i) capacity, material and transport requirement planning modelling; (ii) supply chain production planning problems under uncertainty; and (iii) evolutionary algorithms for fuzzy optimization in production planning.

\section{References}

Bellman, R., Zadeh, L., 1970, Decision making in a fuzzy environment, Management Science 17, 141-164.

Billington, P.J., MCCLAIN, J.O., Thomas, L.J., 1983, Mathematical programming approaches to capacity constrained MRP systems: Review, formulation and problem reduction, Management Science 29, 1126-1141.

Bitran, G., Yanasse, H., 1984, Deterministic approximation to stochastic production problems, 
Operations Research 32, 999-1018.

CPLEX Optimization Co., 1994, Using the CPLEX callable library.

Delgado, M., Kacprzyk, J., Verdegay, J.L., Vila, M.A., 1994, (Eds.) Fuzzy Optimization: Recent Advances, Physica-Verlag, Heidelberg.

De Kok, A.G., Inderfurth, K., 1997, Nervousness in inventory management: comparison of basic control rules, European Journal of Operational Research 103, 55-82.

Dubois, D., Prade, H., 1980, Fuzzy Sets and Systems: Theory and Applications. New York London, Toronto.

Dubois, D., Prade, H., 1988, Possibility Theory. Plenum Press, New York.

Escudero, L.F., 1994, CMIT, capacitated multi-level implosion tool, European Journal of Operational Research 76, 511-528.

Escudero, L.F., Kamesam, P.V., King, A.J., Wets, R.J.B., 1993, Production planning via scenario modelling, Annals of Operations Research 43, 311-335.

Fumero, F., Vercellis, C., 1994, Capacity analysis in repetitive assemble-to-order manufacturing systems, European Journal of Operations Research 78, 61-68.

Gen, M., Tsujimura, Y., Ida, K., 1992, Method for solving multi objective aggregate production planning problem with fuzzy parameters, Computers and Industrial Engineering 23, 117-120.

Gfrerer, H., Zäpfel, G., 1995, Hierarchical model for production planning in the case of uncertain demand, European Journal of Operational Research 86, 142-161.

Guiffrida, A.L., Nagi, R., 1998, Fuzzy set theory applications in production management research: a literature survey, Journal of Intelligent Manufacturing 9, 39-56.

Gupta, A., Maranas, C.D., 2003, Managing demand uncertainty in supply chain planning, Computers and Chemical Engineering 27, 1216-1227.

Heisig, G., 1998, Planning stability under (s, S) inventory control rules, OR Spektrum 20, 215-228.

Hsu, H., Wang, W., 2001, Possibilistic programming in production planning of assemble-to-order environments, Fuzzy Sets and Systems 119, 59-70. 
Inuiguchi, M., Sakawa, M., Kume, Y., 1994, The usefulness of possibilistic programming in production planning problems, International Journal of Production Economics 33, 45-52.

Iskander, M.G., 2002, Comparison of fuzzy numbers using possibility programming: comments and new concepts, Computers and Mathematics with Applications 43, 833-840.

Itoh, T., Ishii, H., Nanseki, T., 2003, A model of crop planning under uncertainty in agricultural management, International Journal of Production Economics 81-82, 555-558.

Kacprzyk, J., Orlovski, S.A., 1987, Fuzzy optimization and mathematical programming: a brief introduction and survey. In: J. Kacprzyk and S.A. Orlovski (Eds.): Optimization Models Using Fuzzy Sets and Possibility Theory, Reidel, Boston, pp. 50-72.

Kira, D., Kusy, M., Rakita, I., 1997, A stochastic linear programming approach to hierarchical production planning, Journal of the OR Society 48, 207-211.

Lodwick, W.A., Bachman, K.A., 2005, Solving large-scale fuzzy and possibilistic optimization problems, Fuzzy Optimization and Decision Making 4 (4) 257-278.

Maximal Software Co., 2000, MPL modelling system, Release 4.11, USA.

Melian, B., Verdegay, J.L., 2005, Fuzzy optimization problems in wavelength division multiplexing (WDM) networks. Proceedings of the fourth conference of the EUSFLAT (European Society for Fuzzy Logic and Technology) and 11 Rencontres Phrancophones sur la Logique Floue et ses Applications (LFA), September 7-9, Barcelona, Spain.

Miller, W.A., Leung, L.C., Azhar, T.M., Sargent, S., 1997, Fuzzy production planning model for fresh tomato packing, International Journal of Production Economics 53, 227-238.

Mula, J., 2004, Models for production planning under uncertainty. Application in a company of the automobile sector, PhD (in Spanish), Polytechnic University of Valencia, Spain. Ed. SP-UPV.

Mula, J., Poler, R., Garcia, J.P., Ortiz, A., 2005, Demand uncertainty effects on first tier suppliers of an automobile industry supply chain. The ICFAI Journal of Supply Chain Management 2 (3) 19-40. Mula, J., Poler, R., Garcia, J.P., 2006a, MRP with flexible constraints: a fuzzy mathematical programming approach, Fuzzy Sets and Systems 157 (1) 74-97. 
Mula, J., Poler, R., Garcia-Sabater, J.P., Lario, F.C., 2006b, Models for production planning under uncertainty: A review, International Journal of Production Economics 103 (1) 271-285.

Negi, D.S., Lee, E.S., 1993, Possibility programming by the comparison of fuzzy numbers, Computers and Mathematics with Applications 25 (9) 43-50.

Paraskevopoulos, D., Karakitsos, E., Rustem, B., 1991, Robust capacity planning under uncertainty, Management Science 37, 787-800.

Pendharkar, P.C., 1997, A fuzzy linear programming model for production planning in coal mines, Computers Operations Research 24, 1141-1149.

Rommelfanger, H., 1996, Fuzzy linear programming and applications, European Journal of Operational Research 92, 512-527.

Sridharan, V., Berry, W., Udayabhanu, V., 1987, Freezing the master production schedule stability under rolling planning horizons, Management Science 33, 1137-1149.

Sodhi, M.S., 2005, Managing demand risk in tactical supply chain planning for a global consumer electronics company, Production and Operations Management 14 (1) 69-79.

Van Donselaar, K.V., Nieuwenhof, J.V., Visschers, J., 2000, The impact of material coordination concepts on planning stability in supply chains, International Journal of Production Economics 68, 169-176.

Wang, R.C., Fang, H., 2001, Aggregate production planning with multiple objectives in a fuzzy environment, European Journal of Operational Research 133, 521-536.

Wang, R.C., Liang, T.F., 2005, Applying possibilistic linear programming to aggregate production planning, International Journal of Production Economics 98 (3) 328-341.

Whybark, D.C., Williams, J.G., Material requirements planning under uncertainty, Decision Sciences 7, 595-606.

Zadeh, L.A., 1965, Fuzzy sets, Information Control 8, 338-353.

Zadeh, L.A., 1978, Fuzzy sets as a basis for a theory of possibility, Fuzzy Sets and Systems 1, 328. 
Zimmermann, H.J., 1996, Fuzzy Set Theory and its Applications. Third Edition. Ed. Kluwer Academic Publishers.

Zimmermann, H.J., 2000, Fuzzy Sets and Operations Research for Decision Support. Beijing Normal University Press.

http://mc.manuscriptcentral.com/tprs Email: ijpr@lboro.ac.uk 


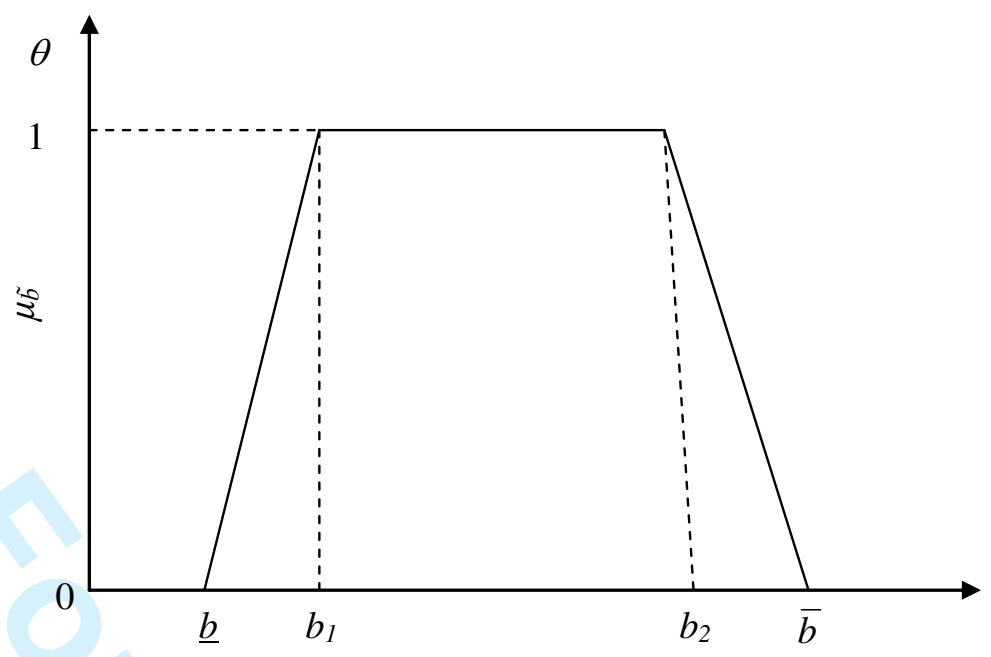

Figure 1. Trapezoidal fuzzy number. 


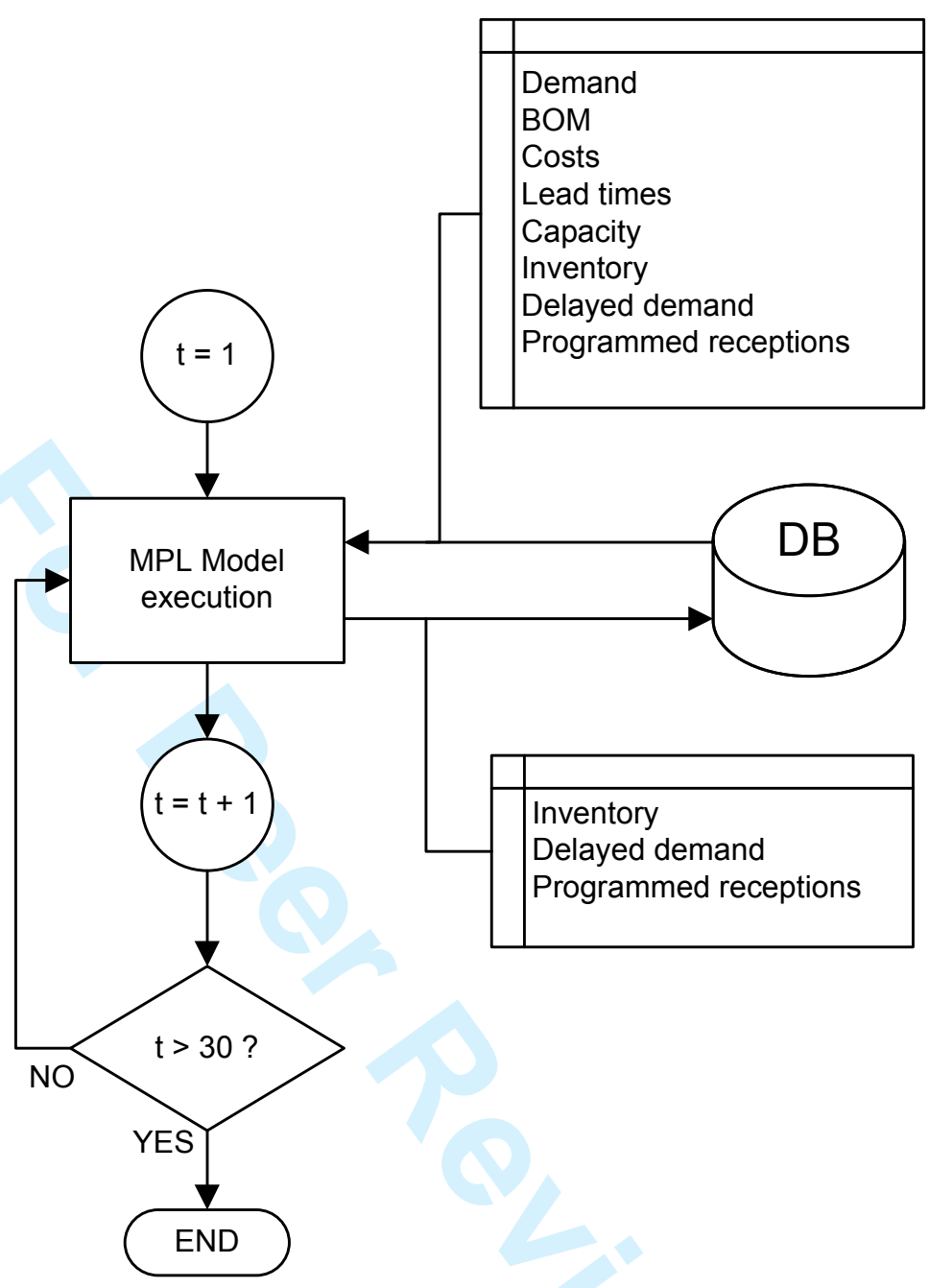

Figure 2. Computational experiment. 
Figure 3. Models architecture.

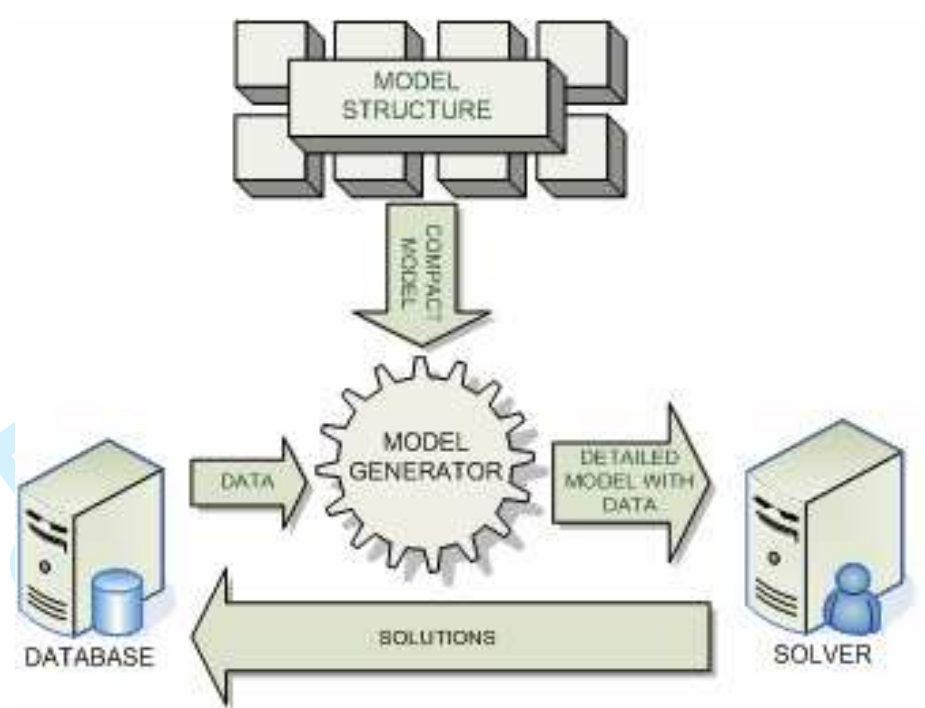


Table 2. Evaluation of the results for all planning horizons.

\begin{tabular}{|l|c|c|c|c|c|}
\hline & Service & $\begin{array}{c}\text { Number of } \\
\text { Minimum } \\
\text { Inventory } \\
\text { Levels }\end{array}$ & $\begin{array}{c}\text { Nervousness } \\
\text { (period) }\end{array}$ & $\begin{array}{c}\text { Planning } \\
\text { Nervousness } \\
\text { (quantity) }\end{array}$ & Total costs (€) \\
\hline LP model & 99.44 & 8 & 0.35 & 14.05 & $3,988,276.07$ \\
\hline Fuzzy model & 99.49 & 35 & 0.35 & 13.05 & $3,635,616.82$ \\
\hline
\end{tabular}


Table 3. Efficiency of computational experiments for only one execution (first week).

\begin{tabular}{|l|c|c|c|c|c|c|c|}
\hline & & & & & Array & Elements \\
Model & Iterations & Variables & Integer & Constraints & $\begin{array}{c}\text { Density } \\
\text { (\%) }\end{array}$ & $\begin{array}{c}\text { CPU Time } \\
\text { (seconds) }\end{array}$ \\
\hline LP model & 0 & 4237 & 5612 & $\mathbf{2 7 9 7}$ & $\mathbf{8 2 3 9}$ & 0.07 & $\mathbf{0 . 8 6}$ \\
\hline Fuzzy model & 0 & 4237 & 5612 & 2977 & 8953 & 0.07 & 3.96 \\
\hline
\end{tabular}

